\section{Contraception and poverty: a lost battle}

\author{
Nisrine N. Makarem \\ Department of Family Medicine, \\ American University of Beirut, \\ Beirut, Lebanon
}

\section{Dear Editor,}

As part of my residency program at the department of Family Medicine at the American University of Beirut, I was sent to an outreach clinic located in the poorest suburbs of Beirut and serving one of the most underprivileged communities in Lebanon. Besides the difficulties of practicing medicine in such settings, one of the greatest challenges of the clinic was the high fertility rates and the very low use of contraceptive methods that were available for free.

The clinic is full of children, every woman walks in with 3-4 children clinging on to her, so closely spaced that you would not know their order of age. Sometimes she herself would stop and think before giving you names or ages. You may wonder why. Why do the poor have so many children? Could the answer be evolutionary? Could it be that like all other mammals, humans also tend to follow a fast evolutionary track when they live in harsh environments?

Lebanon has a contraceptive-use rate of 58\% for any method and a value for fertility rate of 1.76 in 2013, a minimum since 1960., ${ }^{1,2}$ Despite such encouraging figures, contraceptive use is rare among women in this community.

From what women tell us, it seems that men in this community are the ones who demand many children. Women, as they are raised up to be, are obedient to their men's wishes. Some tell us that since they got married right after menarche, or in extreme cases had their menarche while married, rarely get their menses. As one woman recalls, last time I saw blood was ten years ago! Since her marriage, she was either pregnant with one of her 7 children or was breastfeeding.

In this community, men take pride in the number of offspring they have; it is a manifes- tation of how manly and potent they are. Nevertheless, women are also part of the dilemma. Conceiving makes them feel productive and that they are living up to the expectations of their husbands and communities. As another woman explains it: this is what I know to do best.

Furthermore, boredom, lack of electricity, and lack of ordinary life pleasures could be a contributing factor. One of the women joked about it saying that if we had electricity maybe we would spend the night watching television instead of conceiving! As bitter and trivial as this may sound, it could unfortunately be a contributing factor.

The final knock-out to the use of contraception in this community is the endless number of myths surrounding it. Many think that oral contraceptive pills are addictive, while others believe that their effects are irreversible and conceiving after stopping them is almost impossible. The unrealistic fear from irreversible infertility applies to progestin injections whereby the women believe that these work by killing their eggs. Among the most bizarre beliefs about intrauterine devices is that the husband's penis might get tangled to the thread. You try to challenge these myths, but your medical degree, your years of experience, and your scientific proofs all falter and fall when facing these poor powerless women. You realize at this point how poverty has its own culture, how this culture in itself can perpetuate poverty and how these combined can hinder the delivery of proper healthcare in such settings.

What is said above attempts to explain the behavior of underprivileged communities at times of peace, but what happens at times of war? Do the same factors still hold true?

Hay el Gharbeh has become shelter to hundreds of Syrian refugees in the past 2 years. An interesting observation is that 9 out of the 10 women who come for weekly fetal ultrasounds are Syrian. They are pregnant despite being refugees. Many do not know where and how they are going to deliver. Most cannot afford the delivery charges of most Lebanese hospitals; back home their deliveries were at negligible amounts. And then the one million dollar question pops up: But why did you get preg-
Correspondence: Department of Family Medicine, American University of Beirut, Riad El Solh 11-0236, 11072020 Beirut, Lebanon. Tel. +961.3164180 - Fax: +961.1483115

E-mail: nisrinemakarem@hotmail.com

Key words: poverty, contraception, Lebanon, Syrian refugees.

Conflict of interests: the author declares no potential conflict of interests.

Received for publication: 1 March 2013. Revision received: 22 April 2013.

Accepted for publication: 23 April 2013.

This work is licensed under a Creative Commons Attribution 3.0 License (by-nc 3.0).

(C) Copyright N.N. Makarem, 2013

Licensee PAGEPress, Italy

Healthcare in Low-resource Settings 2013; 1:e19 doi:10.4081/hls.2013.e19

nant? We have lost so many martyrs during this war, we want to make up for that is the almost unanimous answer. You then understand that wars can be fought in so many different ways not necessarily with guns and cannons.

The reasons are many, for Lebanese and Syrians, for peace and war, but the outcome is one: an increased burden on this already strained community for the story does not end when the baby is born, it is just when the misery begins.

\section{References}

1. Population Council. Lebanon 1996: results from the Lebanon maternal and child health survey. Stud Family Plann 2001;32:175-80

2. Central Intelligence Agency. The world factbook: Lebanon. Washington, DC: Central Intelligence Agency ed.; 2013. Available from: https:/www.cia.gov/library/ publications/the-world-factbook/geos/le. html 